\begin{tabular}{|l|l|}
\hline & \\
\hline
\end{tabular}

DOSSIÊ

\title{
Pedagogia formal e pedagogia social em mútua dependência
}

Formal pedagogy and social pedagogy in mutual dependence

\author{
Pedagogia formal y pedagogía social en dependencia mutua
}

\section{Hans-Georg Flickinger ${ }^{1}$ orcid.org/0000-0003-3823-7057 zarameurs12@gmail.com}

Recebido em: 11 out. 2019. Aprovado em: 13 mar. 2020. Publicado em: 2 dez. 2020.
Resumo: Ao longo dos últimos anos observa-se no Brasil, o interesse crescente no campo da chamada pedagogia social. A partir de experiências próprias, o autor caracteriza as diferenças entre esse tipo de trabalho pedagógico e a tradicional pedagogia escolar. Defende-se a tese de que as diretrizes subjacentes às atuais politicas educativas estatais desprezam o processo educativo como experiência essencialmente social, contribuindo, assim, ao deslocamento dessa demanda para o espaço fora das instituições fechadas.

Palavras-chave: educação intramuros, pedagogia social, políticas educacionais

Abstract: The growing interest in the field of the so-called social pedagogy has been observed in Brazil along the past years. From the author's own experiences, the differences between this kind of pedagogical work and the traditional school pedagogy are characterized. The paper supports the thesis that the guidelines underlying the current state education policies disregard the educational process as an essentially social experience, thus contributing to the displacement of this demand to the territory outside closed institutions.

Keywords: intramural education, social pedagogy, educational policies

Resumen: A lo largo de los últimos años se observa en Brasil un interés creciente por el campo de la denominada pedagogía social. A partir de experiencias propias, el autor caracteriza las diferencias entre ese tipo de trabajo pedagógico y la tradicional pedagogía escolar. Se defiende la tesis de la presencia de directrices subyacentes a las actuales políticas educativas estatales, que desprecian el proceso educativo como experiencia esencialmente social y contribuyen asi al desplazamiento de esa demanda para el espacio exterior a las instituciones cerradas.

Palabras clave: educación intramuros, pedagogía social, politicas educativas

O sistema educativo é complexo; de dificil acesso, ademais, que sua construção remete a critérios desconcertantes. Tem-se tradicionalmente as faixas etárias que determinam sua institucionalização: jardim de infância e pré-escolar, escola de primeiro e segundo grau, escola profissionalizante, universidades e faculdades, curso de aperfeiçoamento para adultos. Outro critério são as necessidades específicas dos destinatários, tais como portadores de deficiência, analfabetos, marginais, migrantes, presidiários. O debate sobre a política de inclusão nasceu daí. Existe também - terceiro - a diferenciação entre instituições públicas e privadas, que levou ao conflito de competência institucional marcado pelo principio de subsidiariedade. ${ }^{2}$ Como se isso não bastasse, no Brasil das 
últimas três décadas, a distinção entre a educação formal e a não formal, ou seja, entre a educação intramuros e a pedagogia social ganhou força. É, aliás, essa última distinção que nos interessa, aqui, por ter muito a ver com os problemas causados pela sociedade de conhecimento. ${ }^{3}$ Defenderei, a seguir, a tese de que a ascensão da pedagogia social deveria ser entendida como consequência da política de educação comprometida com a competência profissional enquanto objetivo e marca principal do sistema educativo. Na contramão da tradicional ideia de formação, essa política impõe à educação formal uma mudança drástica de seu caráter, que vem sendo completado - na verdade sem tomar consciência disso - no sentido de uma demanda em relação à pedagogia social e ao terreno de sua atuação.

\section{Experiências empíricas}

A maioria das sociedades ocidentais reage à complexidade crescente do sistema educativo com uma política que submete os objetivos da educação às demandas socioeconômicas do mundo neocapitalista. Sua lógica é simples: quanto maior a diversidade das concepções pedagógicas nas instituições educacionais, tanto maior a necessidade de unificar sua atuação e avaliação. Como conseguir isso? A resposta é: mediante a implementação de parâmetros de comparabilidade dos procedimentos e resultados do trabalho. Faz-se, tanto dentro dos Estados quanto entre eles, experimentos com parâmetros quantitativos e, mais precisamente, econômicos e monetaristas. ${ }^{4}$ Em nome da transparência e permeabilidade, recorre-se à quantificação de diferentes qualidades. Como se sabe, uma tal estratégia não consegue englobar todos os aspectos qualitativos; sempre há alguns que não se deixam espelhar em termos quantitativos, o que representa uma grave falha reducionista para a educação. Falha essa que não reduz apenas à motivação quanto à implementação de inovações pedagógicas; o que mais pesa, aí, é o fato de a política dita economicista e monetarista ignorar a educação como espaço de experiências e formação sociais. Assim, desconsiderado pela estratégia de quantificação do processo educacional, esse aspecto essencial só poderá, portanto, ser contemplado fora do campo de educação formal-institucional. Na verdade, a separação entre a educação intramuros e a pedagogia social não passa de um efeito desse reducionismo pedagógico. Dito de outro modo, a aplicação de parâmetros econômico-monetaristas para avaliar a qualidade dos trabalhos educativos não se dá contada função formativa da educação que, como um de seus pilares principais, incluía chance de os envolvidos aprenderem a lidar com os mais diversos modos de relacionamento e convivio sociais. Quais são, portanto, as carateristicas dos dois campos, isto é, aquele da educação formal e aquele da educação informal? Essa pergunta dá, por si mesma, a entender o quanto esses campos relacionam-se um com o outro.

As considerações que seguem fundamentam-se em experiências feitas por mim ao longo de alguns anos no cotidiano da educação formal e não formal; ou seja, nos campos da pedagogia escolar e da pedagogia social.

Nos anos setenta e oitenta do século passado, o currículo que definia a formação de professores escolares e de pedagogos sociais, na Universidade de Kassel, previa tanto o estágio prático obrigatório dos alunos em uma instituição pública quanto aquele em um projeto pedagógico a ser realizado fora das instituições regidas por duras restrições. As experiências dentro e fora da instituição eram ademais acompanhadas de reflexão científica em seminários paralelos, oferecidos pela faculdade.

Recém chegado à Universidade, fui convidado a orientar esse tipo de trabalho teórico. Acompanhei, primeiro, um projeto estudantil intitulado "Formação política da juventude na província"; projeto esse realizado em cooperação com a

\footnotetext{
Trata-se do tipo de sociabilidade construido pelo conhecimento individual e coletivo. Por isso, o conceito refere-se à sociedade atual com sua aposta na tecnologia de informática.

4 A lavagem de dinheiro dá a entender o corte dos laços do dinheiro em relação a sua origem material-concreta. É o que subjaz à economização e monetarização da educação.
} 
Igreja protestante local. Os estudantes tiveram, aliás, a sorte de a cúpula administrativa da lgreja não ter imposto regras restritivas no que se refere à realização das ideias defendidas por eles. Sem ser profissional no campo pedagógico - uma vantagem que só percebi ao longo daquele trabalho - aceitei o desafio. Tomando a sério o papel de interlocutor científico-crítico nas discussões sobre as experiências práticas dos estagiários, aprofundei meu conhecimento das então acirradamente discutidas teorias sobre a pedagogia não formal da juventude. ${ }^{5}$

Confrontando meu conhecimento teórico com os relatos dos estudantes, aprendi muito sobre os desafios e as especificidades do trabalho nos dois campos pedagógicos. O que, contudo, imprimiu-se com mais força em minha lembrança, foi um efeito aparentemente colateral, embora decisivo para meu engajamento posterior nos debates sobre a filosofia da educação. A saber: foi a participação no referido projeto - e, pouco depois, também em um projeto estudantil com trabalhadores imigrantes em cooperação com uma liga filantrópica - que me abriu os olhos para a relação nada fácil entre os profissionais da educação intramuros e aqueles da pedagogia social. Na opinião dos educadores intramuros, a educação formal, em particular a escolar, precisaria de profissionais de excelente qualificação disciplinar, capazes de passar seu conhecimento aos alunos; ao passo que, naquela dos pedagogos sociais, o que mais importava em um profissional do ensino era a capacidade de acompanhar as experiências formativas dos jovens em espaço aberto, vale dizer, fora da instituição, orientando-os e apoiando-os na defesa de seus interesses e na estruturação de suas experiências sociais. Por um lado, estaria, portanto, o educador com um chão profissional assegurado, mas submisso às diretrizes do detentor da instituição e com mínima liberdade de fazer experiências com ideias pedagógicas novas; e, por outro, o pedagogo social agindo em um espaço aberto e pouco sujeito a regras de orientação profissional, já que a ele cabia sobretudo fazer valer os interesses dos educandos. Se o primeiro cumpriria sua missão fazendo valer os objetivos prescritos pelas diretrizes institucionais, o segundo via-se obrigado a aceitar a incerteza causada pela negociação permanente com os jovens, não só quanto aos objetivos, senão também quanto conteúdos e procedimentos do trabalho.

Diante desse cenário surgia, naturalmente, uma série de indagações referentes sobretudo à pedagogia social. Como, por exemplo, explicara preocupação pedagógica crescente com o trabalho educativo fora das instituições fechadas? Qual seria efetivamente a sua função no processo de formação dos jovens? O pedagogo social deveria apenas compensar as falhas da educação intramuros? Haveria uma interdependência entre ambas as orientações? Verdade é que o próprio autoentendimento de muitos pedagogos sociais oscilava entre a função de reagir aos défices da educação intramuros, e aquela de agir enquanto autêntico representante da melhor ideia de formação.

\section{As caraterísticas dos campos de trabalho}

Antes de respondermos às questões apontadas, teremos de caracterizar as especificidades dos dois campos de educação. Diante da variedade de suas manifestações concretas, remeterei a sua estilização como tipos ideais (Max Weber).

A educação intramuros. Falemos primeiro sobre as condições do processo educativo dentro das instituições. Na sua maioria elas são públicas. O fato de essas condições verem-se expostas a reformas contínuas pela politica dificulta a orientação a quem busque acesso ao sistema no seu todo. Falta transparência. Mesmo assim, dá para, com maior ou menor visibilidade, apontar marcas gerais em toda educação intramuros. Qualquer institucionalização do processo educativo afeta a autonomia dos envolvidos, sobretudo quando

\footnotetext{
5 Na época, autores como Nando Belardi, Hermann Giesecke, Dieter Damm e Klaus Mollenhauer eram os protagonistas desse debate Ver também C. Schweppe e S. Sting (2006). Uma voz importante no Brasil é Graciani (1999; 2014).
} 
se trata de instituições com aspectos típicos de uma instituição total. ${ }^{6} \mathrm{~A}$ escola tradicional é um caso exemplar. Ai salta aos olhos - primeiro - a restrição da mobilidade espaço-temporal, que as regras dessas instituições impõem. A obrigação de submeter-se ao ritmo prescrito pela instituição é, na verdade, vista como restrição da liberdade pessoal referente à vida cotidiana. Acrescenta-se a isso - segundo - o dever legal de frequentar a instituição sob o controle do Poder público. Trata-se de uma comunidade encenada, na qual cada internado é obrigado a lidar com pessoas alheias, colegas e profissionais com caracteres diferentes e nem sempre simpáticos. Uma obrigação que, não raro, reduz a motivação do individuo de entregar-se aos trabalhos coletivos. Regras e diretrizes determinam a vida pessoal e os procedimentos institucionais. Terceiro: aprende-se conteúdos predefinidos por currículos impostos de fora, sem maior consideração de demandas e interesses dos jovens. O processo educativo - o quarto ponto - concentra-se cada vez mais na transferência de conhecimentos objetivos, desvinculados das necessidades subjetivas, ampliando assim o abismo entre as experiências intramuros e a vida cotidiana. Exemplo recente é o conflito em torno da implementação de tecnologias digitais na escola. Por um lado, não se pode mais imaginar o ensino sem levar em consideração a presença dessa tecnologia no dia a dia dos jovens; por outro, seu uso em sala de aula precisa ser restrito a informações objetivas, com vistas a garantir um melhor aprendizado, sem desviar a atenção do aluno.

É claro que o tipo instituição total facilita controlar o processo educativo mediante critérios tidos como objetivos e independentes das condições particulares das pessoas envolvidas. Uma concepção, porém, que tem seu lado perigoso, pois ela implica também em uma avaliação objetificadora do processo educativo. Visto deste ângulo, não pode surpreender certa dinâmica atualmente presente na política educativa: essa vem de modo crescente utilizando-se de cálculos econômicos de avaliação. Recorrendo ao modelo de relacionar input e output, essa política prevê que a aplicação dos recursos materiais e humanos deveria levar a resultados por ela considerados adequados. A medição, portanto, dessa relação faz-se tendo em vista uma quantificação monetária, falando-se acerca da economização e monetarização da educação. Contudo, por mais objetivo e justo que pareça ser esse tipo de avaliação do sistema educativo, ele contém uma falha séria; a saber, a impossibilidade de levar em consideração as condições pessoais e experiências sociais como fatores reais do processo formativo. As pessoas concretas contam apenas enquanto capital humano. Por trás da máscara dos critérios quantitativos, elas desaparecem no cálculo econômico. Capital humano - uma expressão traiçoeira que, não por acaso, mostra hoje a careta no linguajar da política educativa.

Não se deve subestimar também outro risco provocado pelo sistema formal da educação. Falo da possibilidade de instrumentalizar a instituição em favor de determinadas ideologias. Sabe-se que o comprometimento ideológico das instituições interfere, até com certa naturalidade, também na formulação das diretrizes pedagógicas a serem respeitadas no trabalho. Não é um risco apenas no caso das instituições privadas, cujos detentores têm até o direito de fazer valer suas convicções ideológicas no trabalho;7 ele atinge também as instituições públicas. ${ }^{8}$ Tanto os profissionais quanto os educandos são obrigados a respeitar as diretrizes ideológicas sem ou apenas com pouca chance de dar voz as suas próprias convicções. Quem não se submete a tais exigências ideológicas corre o perigo de ser marginalizado ou até mesmo perder seu lugar na instituição.

Como se vê, à base dessas poucas caraterísticas, as imposições restritivas da instituição tornam-se uma camisa de força, na qual ficam metidos os protagonistas. Não que se queira negar a importância de regras e diretrizes para

\footnotetext{
O conceito é de Erving Goffman (1974).

Trata-se da consequência do principio de subsidiariedade: os detentores privados por exemplo das escolas Waldorf, de jardins de infância ou de universidades particulares têm essa regalia ideológica.

8 Basta lembrar o debate político sobre "a escola sem partido" - como se esse lema não expressasse também uma determinada ideologia.
} 
organizar o trabalho educativo intramuros; mas, comprometidas com a economização e monetarização do sistema, elas levam a uma falha comum muito séria. A saber, à negligência ou até mesmo ao recalque das experiências essencialmente sociais enquanto fatores decisivos de qualquer conceito de formação. Pois bem, o que marca o atual sistema da educação formal-intramuros é justamente a cegueira em relação a esse aspecto.

A pedagogia social. Na verdade, a denominação pedagogia social é uma expressão equivocada por insinuar que exista, de fato, uma pedagogia sem componentes essencialmente sociais. Sobre isso mais tarde!

A ascensão da pedagogia social na Europa do século XIX aconteceu sob a égide de movimentos sociais e de ligas filantrópicas, ligadas sobretudo à Igreja. A industrialização desenfreada, à época, além das guerras devastadoras, promoveram o desenraizamento de grande parte da juventude de seu solo social razoavelmente seguro. Foi o desamparo das jovens gerações que, desenhando-se como ameaça ao futuro da sociedade, acordou a política social. Ali, onde os esforços da sociedade civil não surtiam o efeito desejado, o Estado obrigou-se a entrar em cena. Ainda assim, foi necessário encontrar uma solução à relação belicosa entre os serviços sociais do Poder público e das associações civis, tendo com isso a origem ao que se denominou o principio de subsidiariedade. De fato, é até hoje à sua base, que o Estado concede às instituições da sociedade civil - Igreja, associações filantrópicas, fundações civis etc. - a prioridade em relação aos problemas sociais da juventude. Com certa demora, essa concepção, articulada pela Igreja Católica já no final do século XIX, entrou também na política social do Brasil. Hoje, o tema está presente nos debates sobre a reação adequada da educação aos efeitos sociais do mundo moderno. ${ }^{9}$

Antes de falarmos acerca das tendências atuais, vale lembrar as caraterísticas da tradicional educação não formal sob a tutela de organizações civis.

Em primeiro lugar, há de se nela sublinhar o caráter voluntário da participação nas atividades oferecidas pelas organizações civis. Sem obrigação legal, os jovens podem decidir livremente aproveitar-se ou não das oportunidades de fazer experiências formativas fora das restrições de instituições do tipo total. Vários motivos podem influenciar essa decisão: o interesse particular no tema; a chance de estar junto a determinados companheiros; a curiosidade quanto a uma possivel aventura; a simpatia com o/a profissional responsável; a chance de auto-organização das experiências etc. De qualquer modo, a escolha dependerá de preferências pessoais não contestadas por regras institucionais. É essa liberdade que atrai e impulsiona as atividades coletivas e as chances de aprender com elas.

O critério de voluntariedade permite também eis o segundo aspecto - a escolha da organização que oferece o espaço educativo. Trate-se de uma comunidade de base, de uma organização não governamental (ONG), de um projeto oferecido pelo municipio ou de alguma subcultura juvenil, abre-se aos interessados a oportunidade de escolher o campo de atividades que mais prometa corresponder as suas expectativas e necessidades. Em contrapartida à instituição intramuros, tais organizações renunciam às regras estritas, buscando deixar sua clientela o mais livre possivel.

Como terceira característica, menciono os principios de cogestão e auto-organização, à base dos quais desdobram-se aí as experiências e a aprendizagem. As decisões são tomadas coletivamente sem obedecer a rituais impostos por alguma hierarquia formal; fato esse que leva todos a compartilhar a responsabilidade pela escolha, pelo andamento e pelos resultados do trabalho em comum. Experimentam-se ai, as diversas formas de interação, tais como lidar com divergências, ouvir os parceiros, ponderar argumentos e chegar a decisões aceitas em conjunto. Suas marcas são a abertura e a flexibilidade da organização.

O quarto aspecto típico da concepção tradicional da pedagogia social é a aprendizagem vinculada à experiência concreta. Learning by

9 Ver recentemente Christoph Türcke (2019, p. 56) 
doing - eis o modelo pedagógico que prevalece. Independentemente de qualquer autoridade com principios e verdades supostamente inquestionáveis, são os próprios protagonistas que escolhem seus interesses temáticos, os critérios de sua realização, as regras a serem seguidas, e o procedimento. São, neste caso, a cooperação e o convivio social as condições necessárias para alcançar os resultados esperados.

O quinto aspecto remete às condições da aprendizagem fora da instituição, e diz respeito também ao papel e ao autoentendimento dos profissionais envolvidos. Esses têm, em geral, dificuldade em lidar com um espaço pedagógico não claramente estruturado por regras e objetivos institucionais. Em principio, o pedagogo social não passa conhecimentos objetivos à base de um currículo, senão incentiva sua clientela a construire refletir as condições sociais necessárias para levar adiante os trabalhos e as experiências realizados no grupo. Lançado, assim, em um espaço aberto, e sem autoridade institucional assegurada, esse profissional vive o permanente risco de ter seu papel questionado pelos jovens. Não é de se admirar que essa porosidade em sua identidade profissional possa criar-lhe problemas. Pois, afinal - fiel ao lema do Serviço Social, a saber, o da "ajuda para a autoajuda" - sua função pedagógica poderia reduzir-se à assistência ao andamento do trabalho e à reflexão das experiências

Como se vê, essas carateristicas da pedagogia social dão a entender nela um núcleo principal: enfatiza-se ai a formação do individuo e a conquista de experiências sociais em detrimento do mero conhecimento técnico-científico e prático. Nela, o que deve ser tomado a sério é justamente o caráter formativo da educação, desprezado pela política educacional recente. A pedagogia social denuncia, assim, o reducionismo pedagógico dessa política comprometida com o critério da competência profissional.

Simultaneamente, porém, o que ai se anuncia é uma certa dinâmica no relacionamento mútuo desses dois campos de educação: na medida em que a educação formal intramuros negligencia as experiências sociais como fator constitutivo da formação, são a importância e a responsabi- lidade da pedagogia social que emergem à vista, apontando a necessidade de realizar seu ideal. Não seria essa, acaso, um sensório apontando aos problemas da educação intramuros? Não é ela, afinal, que toma, desde a origem, as experiências sociais como parte integrante da ideia de formação? Não é esse o seu cerne e desafio principal? Longe, portanto, de tratá-la como uma simples compensação das falhas causadas pela política educativa - eis a opinião maioritária -, penso que deveriamos prestigiar o papel autêntico dos pedagogos sociais na defesa da ideia de formação.

\section{A importância crescente da pedagogia social}

Tendo-se em vista as caracteristicas marcantes desses dois campos de educação, têm-se uma visão geral de suas diferenças tradicionais. Não se entendeu, porém, ainda, é o que me parece, a dinâmica contida no cenário atual, que sublinha a importância da pedagogia social. Uma importância que se denuncia talvez, sobretudo, a partir dos efeitos da política educativa recente junto às conquistas da tecnologia de informática e as mudanças de hábitos e práticas sociais provocadas por elas.

Eu explico: na medida em que a política vem tratando a educação pelo viés de sua economização e monetarização, ela abandona a formação da pessoa em favor de sua competência profissional, e despreza, com isso, as experiências sociais formativas como fator pedagógico essencial. Como recuperar e fazer valer, outra vez, esse fator? Sim, como realizá-lo frente aos avanços recentes no mundo digital? Na medida em que a política educacional deixou de respeitar esse fator essencial na formação dos jovens, parece-me necessário salientar o papel da pedagogia social, levando-a a assumir essa tarefa sob as condições de sociabilidade novas. Mas aqui temos de apontar nova dificuldade: a pedagogia social dos anos sessenta e setenta não se insere no mesmo cenário da atual, precisando ela mesma lutar com o seu próprio desnorteio.

Não por acaso fala-se hoje de uma nova cultura de aprendizagem, provocada pelo mundo digital. Formas de comunicação social até então 
incomuns; laços sociais instáveis graças à anonimidade dos interlocutores; a perda do diálogo vivo como espaço argumentativo; agressões sociais de dificil controle, tais como o mobbing e bullying; a desmedida das informações, com o problema das fake news; a prioridade do olhar em detrimento do ouvir na apresentação do saber - eis apenas alguns dos fatores - no reino da lógica de economização da educação e da tecnologia digital - indicativos da desatenção às experiências social-formativas avançadas. Pois bem, é diante desse cenário que nos salta agora aos olhos a diferença entre a pedagogia social tradicional e aquela atualmente vigente: enquanto nos anos sessenta e setenta a famosa Escola de Birmingham via na então cultura da juventude um modo de resistência ao ambiente social dominado pelo materialismo capitalista, ${ }^{10}$ hoje os jovens tendem a construir o seu mundo social em conformidade com seu ambiente. Eles, de fato, não recorrem mais à tutela de alguma instituição, entregando-se antes à realidade vivida. Suas "instituições" são hoje as plataformas da Internet, as redes sociais como espaço aparentemente neutro e um mundo que promete ao indivíduo a total liberdade. Cada um decide sobre o tamanho de sua integração no universo da sociabilidade digital. Posicionar-se, nesse universo, e apreender junto a ele tornou-se um processo coletivo. Cada um é parte integral sem risco de ser tutelado por qualquer instância alheia. Um exemplo paradigmático desse tipo de sociabilidade do saber é a Wikipédia, cuja marca é a manipulação jocosa do instrumentário tecnológico.

Para a pedagogia social trata-se, pois, de um campo novo de integração social. Mediatizado pela tecnologia digital, a sociabilidade nova alimenta-se do potencial de uma tecnologia, à qual os individuos se acomodam. Em outras palavras, é a tecnologia e não mais o individuo que constrói as experiências sociais e as sustenta. Em vista disso, qual é o desafio? Em primeiro lugar, os jovens deveriam dar-se conta da "sociabilidade" a eles imposta pelo mundo digital, que manipu- la sua suposta liberdade. Segundo: a tarefa do pedagogo social seria denunciar a manipulação trazendo à tona os riscos nela inscritos. Submissão ao mundo digital ou sua aceitação consciente, aliada à resistência crítica a ele, vale dizer, sem conformidade, eis os dois polos do mesmo processo formativo. Que os jovens tomassem uma decisão consciente à alternativa de uma submissão que se vem fazendo de modo crescente. Terceiro: compreender as experiências sociais como efeito do mundo digital significa também detectar/denunciar o desprezo desse mundo pela ideia da formação pessoal. Quarto: o pedagogo social afinaria o olhar dos jovens a apanhar criticamente, tanto na sensibilidade quanto na reflexão, o processo deformante, exercido pelo mundo digital. Sem esses passos, a pedagogia social perderia de vista o objetivo de recuperar a ideia de formação - e sua legitimação de ser.

Como se vê, o caminho da pedagogia social reage à política educativa e aos efeitos advindos da pedagogia formal, lembrando-a de suas falhas. E, vice versa, a pedagogia social se reconhece nessas falhas e aceita o desafio que isso implica. Ambas se enlaçam nesse processo, apontando a algo novo, em esboço, e arriscado.

\section{Referências}

BELARDI, N. (1975). Erfahrungsbezogene Jugendbildungsarbeit. Achenbach-Verlag: Gießen.

CLARKE, J. (1979). Jugendkultur als Widerstand. Frankfurt am Main: Syndikat.

DAMM, D. (1975). Politische Jugendarbeit. Weinheim/ München: Juventa-Verlag.

GIESECKE, H. (2009), Pädagogik - quo vadis?, Weinheim/München: Juventa-Verlag.

GOFFMAN, E. (1974). Manicômios, prisões e conventos. São Paulo: Editora Perspectiva.

GRACIANI, M. S. S. (1999). Pedagogia social de rua. São Paulo: Editora Cortez.

GRACIANI, M. S. S. (2014). Pedagogia social. São Paulo: Editora Cortez.

MOLLENHAUER, K. (1970). Erziehung und Emanzipation. 4.Auflage. München: Juventa-Verlag.

10 Entre os protagonistas dessa concepção destacam-se Paul Willis (1982) e John Clarke (1979). 
SCHWEPPE, C., \& STING, S. (2006). Sozialpädagogikim Übergang. Weinheim: Beltz-Verlag.

TÜRCKE, C. (2019). Digitale Gefolgschaft: auf dem Weg zu einerneuen Stammesgesellschaft. Stuttgart: Verlag C.H.Beck. https://doi.org/10.17104/9783406731822.

WILLIS, P. (1982). Spaß am Widerstand. Frankfurt am Main: Syndikat-Verlag.

\section{Hans-Georg Flickinger}

Doutor em Filosofia pela Universidade de Heidelberg. em Heidelberg, Alemanha; professor Emeritus da Universidade de Kassel, em Kassel, Alemanha.

\section{Endereço para correspondência}

Hans-Georg Flickinger

Universidade de Kassel

Mönchebergstraße 19, 34125

Kassel, Alemanha 